PYROLYSIS AND GASIEICATION OE COAL AT HIGH TEMPERATURES

Grant Number DE-EG22-87PC79930

DOE/PC/79930--T15

ANNOAL PROGRESS REPORT

(Year \#1 : 9/15/1987 to $9 / 15 / 88$ )

DE93 007681

\begin{abstract}
PRINCIPAL INVESTIGATOR: Prof. Kyriacos Zygourakis
Department of Chemical Engineering

Rice University

Houston, Texas 77251-1892

Tel. (713) 527-8101 Ext. 3509.

PROJECT MANAGER: Dr. James Longanbach

Morgantown Energy Technology Center

PO Box 880

Morgantown, West Virginia 26505.

GRANT PERIOD:

$9 / 15 / 1987$ to $9 / 14 / 1990$
\end{abstract}

1987-88 PROGRAM SCHEDULE

$\begin{array}{lllllllllllll}S & O & N & D & J & E & M & A & M & J & J & A & S\end{array}$

A. Pyrolysis Studies

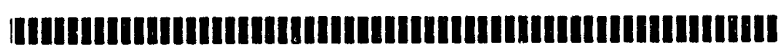

B. Gasification Studies

|m+m|n!II!

IIII

C. Dev'slopment and Validation of

Mathematical Models for Char Gasification

\title{
|
}

US/DOE Patent Clearance is not required prior to the publication of this document

DISTRIBUTION OF THIS DOCUMENT IS UNLIMITED 


\section{BACKGROUND STATEMGNT}

Pyrolysis is the first stage of direct coal utilization processes. As coal particles are heated in a reactor, they release most of their volatile constituents in the form of gases and tars. The chemical transformations characterizing the pyrolysis stage are accompanied by complex morphological transformations that determine the pore structure and, consequently, the reactivity of the produced chars during the subsequent combustion or gasification stage.

The major factors affecting the macropore structure of chars are the rank of the parent coals and the pyrolysis conditions. Coals can be broadly categorized as plastic or non-plastic according to their behavior during pyrolysis. Plastic coals soften as they are heated up and behave as highly viscous non-newtonian fluids over a broad temperature range. Three phases are found to coexist during this plasticity stage: a viscous (but optically isotropic) coal melt, an anisotropic liquid crystalline phase and a gaseous phase. The volatile gases form bubbles that grow and coalesce swelling the coal particles and leading to the formation of highly cellular internal pore structures that are characteristic of chars derived from plastic coals. Non-plastic coals, on the other hand, do not soften and do not undergo drastic macropore structure transformations during the pyrolysis stage. Bituminous and subbituminous coals are generally considered to be plastic, while lignites and other low rank coals belong to the non-plastic category.

The operating conditions influencing most strongly the pyrolysis process are the heating rate, the particie size and the pressure. Existing literature data offer little quantitative information on the effect of operating conditions on macropore structures, since the majority of past studies have concentrated on studying the kinetics of pyrolysis reactions and the distributions of the obtained products. Previous studies (Howard, 1981; Oh et al., 1984), however, indicate that the kinetic and transport processes occurring during pyrolysis (such as the rate of volatile release, the diffusion of volatiles into the bubbles, the transport of volatiles to the particle exterior etc.l will be governed by the time-temperature history of the coal particles. Hence, the pyrolysis heating rate is expected to have the strongest effect on the macropore structure of the chars (Hamilton, 1981).

After the short pyrolysis stage, the char particles are gasified in various reacting atmospheres. Gasification processes are usually diffusion-limited since the various heterogeneous reactions take place at elevated temperatures. Low utilization of the surface area associated with the micsopores present in chars is expected under such conditions. Reactions occur mostly in the larger macropores that are close to the particle exterior and pore accessibility to reactants becomes a major factor in determining gasification rates. Initially, internal pores may be inaccessible to reactants. As the reaction proceeds, however, walls of closed pores will burn away exposing surface area previously unavailable for reaction and leading to substantial particle fragmentation. The opening of closed porosity, the formation of a progressively more tortuous particle exterior and the fragmentation of the original particles can lead to large enhancements of the observed gasification rates.

\section{PROJECT DESCRIPTION AND OBJECTIVES}

Coals of different rankg will be pyrolyzed in a microscope hot-stage reactor using inert and reacting atmospheres. The effects of pyrolysis conditions (heating rates, particle size, inert or reacting atmosphere etc.) on the macropore structure of the produced chars will be quantified using video microscopy and digital image processing techniques. Devolatilized chars will be gasified 
in the regime of strong intraparticle diffusional limitations (high temperatures). Direct measurements on video images of char particles gasified in the microscope hot-stage will yield quantitative data on particle shrinkage and fragmentation. Gasification rates will be obtained on a thermogravimetric reactor. In addition, probabilistic gasification models will be developed and validated. Comparative aralysis of gasification data and theoretical predictions will identify the fundamental phenomena that must be included in accurate predictive models for the gasification of coal particles under actual process conditions.

\section{RESUITS AND ACCOMPIISHMENTS}

\section{TASK A: EEEECTS OF PYROLYSIS CONDITIONS ON MACRORORE STRUCTURE}

\section{Effects of Pyrolysis Heating Rate}

A plastic coal (Illinois *6) was studied first. Coal particles in the 50-60 mesh $(250-300 \mu \mathrm{m})$ range were pyrolyzed in a captive sample microreactor at five different heating rates: $0.1,1.0,10,100$ and $1000^{\circ} \mathrm{C} / \mathrm{s}$ Char particles collected from ten runs at each set of conditions were embedded in an epoxy-resin block, and one side of the block was polished to reveal random cross-sections. For each char sample, we acquired digitized grey-level images of 40 to 50 particle cross-sections. These images were then segmented in order to identify the two-dimensional macropore cross-sections or pore profiles. Fig. 1 presents binary images of representative cross-sections of char particles produced at the various heating rates. The black areas of these images correspond to the char matrix, while the internal white areas are the cross-sectional profiles of macropores.

The lowest heating rate $\left(0.1^{\circ} \mathrm{C} / \mathrm{s}\right)$ produced char particles exhibiting a few scattered large cavities with thick walls and several smaller cavities. This is consistent with the accepted pyrolysis mechanism involving formation and $g r o w t h$ of volatile gas bubbles. Note that most of the particles shown in Fig. $1 \mathrm{~A}$ have retained their angular shape and only a few cenospheres were observed. Calculations indicated a moderate pressure buildup in the particle interior, since the volatile production rates are slow enough to let the gas escape before the bubbles can grow to a large size. At faster heating rates, however, the volatile production rates increase substantially leading to considerably higher pressures in the particle interior and, thus, to larger bubble sizes and more particle swelling. At a heating rate of $1{ }^{\circ} \mathrm{C} / \mathrm{s}$, the formation of several thin-walled cavities was observed (Fig. 1B) and several pyrolyzed char particles started exhibiting a distinct cellular internal structure. At still higher heating rates, the cellular internal structure was dominant. Chars pyrolyzed at 100 and $1000^{\circ} \mathrm{C} / \mathrm{s}$ showed exclusively thin-walled cellular structures with a few large cavities and a group of smaller secondary vesicles formed in the thin walls of the larger ones. One should note also that large particle swelling occurs at the higher heating rates leading to particles with very high porosity.

Pyrolysis heating rates had a much smaller effect on the macropore structure of chars produced from a non-plastic lignite coal (Wilcox, Texas). Earlier indirect measurements have indicated that the initial macropore network of non-plastic (low rank) coals remains essentiaily intact during pyrolysis (Gavalas and wilks, 1980). In order to study the effect of pyrolysis heating rate on the lignite char structure, coal particles in the the 50-60 mesh size range tyere pyrolyzed in our microreactor at three heating rates $10.1,10$ and 1000 - $\mathrm{C}(\mathrm{s})$. Fig. 2 shows representative images of the polished char sections taken for each sample. In contrast to the Illinois*6 chars, the cross-sections of lignite char particles show almost no visible change as the heating rate is increased. A comparison of particle sections obtained from the pyrolyzed chars 
and the parent coal revealed that several large fractures and cracks were formed during the pyrolysis stage.

\section{Characterization of the Macropore Structure}

Quantitative characterization of the macropore structure of the chars was performed using digital image processing and analysis techniques. The binary images of particle cross-sections were combined in a mosaic and the composite j.mage was analyzed to obtain statistics for the population of two-dimensional pore profiles.

\section{(i) Stereological Properties Estimated without Geometric Assumptions}

Two important stereological properties, the macroporosity $\varepsilon$ and the macropore surface density $S_{v}$ can be estimated from two-dimensional pore profiles without any restricting assumptions concerning the geometrical shape of the macropores (DeHoff, 1983). In order to obtain these estimates, our image analysis software was modified to compute the following cumulative quantities.

- $A_{a}=$ total cross-sectional area of two-dimensional macropore profiles.

- $A_{c}=$ total area of char particles (pores plus char matrix).

- $B_{a}=$ total length of the boundary length (or perimeter) of pore profiles.

Estimates of the macroporosity $\varepsilon$ can be obtained (Weibel, 1980) from the two-dimensional particle cross-sections using the formula

$$
\varepsilon=\frac{A_{a}}{A_{C}}
$$

while an estimator of the macropore surface density $\mathrm{S}_{\mathrm{v}}$ (expressed in $\mathrm{cm}^{2}$ of pore surface area per $\mathrm{cm}^{3}$ of char particle) is given by

$$
S_{v}=\frac{B_{a}}{A_{c}}
$$

We must emphasize again the generality of the above formulae that provide estimates of $\varepsilon$ and $S_{v}$ without any restricting assumptions concerning the geometrical shape of the pores.

\section{(ii) Stereological Properties Requiring Geometric Assumptions}

We have also investigated the problem of obtaining the macropore volume distributions, a property that is necessary for estimating key parameters of gasification models. The calculation of the size distribution of three-dimensional pores from two-dimensional pore profile data requires assumptions regarding the shape of the macropores.

We have chosen to model the macropores as non-overlapping spheres whose radii $R$ have an unknown probability density function $F(R)$. The assumption of spherical macropores is clearly supported by the digitized images presented in Figs. 1 and 2. Circular pore profiles will be obtained if we section the macropore structure with random planes. In our case, this sectioning is achieved experimentally by preparing the polished section specimens described above. The area of each pore profile $A_{i}$ is directly measured and an area-equivalent radius $r_{1}$ for this profile is computed from the formula

$$
r_{i}=\sqrt{A_{i} / \pi}
$$


Thus, the size distribution $f(r)$ of the pore profiles can be easily obtained from the digitized images of particle cross-sections. We must then solve an integral equation in order to "unfold" the size distribution of the spherical pores from the two-dimensional pore profile data. In our early attempts to solve this problem, we employed a "histogram" method that involved (a) B-spline smoothing of the cumulative sample frequency function and (b) a finite-difference method with trapezoidal rule integration for the solution of the integral equation. Although the smoothing of the data alleviated some of the well-known problems associated with such inversion methods (Taylor, 1982), the choice of the smoothing parameters introduced some degree of arbitrariness in the sphere size distributions obtained. We are currently reformulating this "unfolding" problem using a maximum likelihood statistical method. Preliminary results indicate that our new approach is much more robust in the presence of large data scatters introduced by the sampling process.

This stereological model yields the numerica! density $N(R)$ of the spherical macropores, where $N(R) d R$ is the fraction of pores with radii between $R$ and $R+d R$. Thus, we can easily calculate the macropore volume distribution and another estimate $S_{s}$ of the macropore surface area density as

$$
s_{s}=4 \pi \int_{0}^{\infty} R^{2} N(R) d R
$$

We must note here that this stereological model implicitly assumes smooth spherical macropores. Since the actual macropore profiles reveal very tortuous pore boundaries, the estimate $S_{s}$ is expected to be much lower than the true surface area density $S_{v}$.

\section{(iii) Structural Measurements}

Table I presents the structural properties of the Illinois \#6 chars produced at various heating rates. Increasing heating rates produced chars with consistently higher porosity and maximum pore radius. The increase in porosity, however, tends to level off at the higher heating rates. An increase in the macropore surface area density $S_{v}$ was observed as the pyrolysis heating rate increased from 0.1 to $10^{\circ} \mathrm{C} / \mathrm{s}$. However, $S_{v}$ decreased at higher heating rates due to the appearance of very large pore cavities in the highly-swollen char particles (see Figs. $1 D$ and $1 E$ ). The property of interest for reaction engineering calculations, however, is the specific macropore surface area $S_{g}$ expressed in $\left(\mathrm{cm}^{2}\right.$ pore surface)/( $\mathrm{cm}^{3}$ solid char). Table I shows that $\mathrm{S}_{\mathrm{g}}$ increased dramatically with increasing heating rates. This is an indication that Illinois $\# 6$ chars produced at high pyrolysis heating rates will be more reactive at elevated temperatures where low utilization of the micropores is expected. Note that both $S_{v}$ and $S_{g}$ were obtained from the basic stereological properties without any assumptions concerning the shape of macropores. Table I also presents the macropore surface area densities $S_{s}$ calculated via the stereological model discussed above. As expected, $S_{s}$ is considerably smaller than $S_{v}$ for all char samples.

Table II presents the basic structural properties for the lignite chars. These stereological measurements show small effects of the pyrolysis heating rate both on the particle porosity and on the specific macropore surface area $S_{g}$ of the char samples.

\section{DISCLAIMER}

This repout was prepared as an acceunt of work sponsored hy an agency of the United States Government. Neither the United States Government nor any agency thereof, nor any of their Government. Neither the United States Government nor any agency thereor, nor any of their bility for the accuracy, completeness, or uscfulness of any information, apparatus, product, or process disclosed, or represents that its use would not infringe privately owned righ:s. Reference herein to any specific commercial product, process, or service by trade name, trademark, manufacturer, or otherwise does not necessarily constitute or imply its endorsement, recommendation, or favoring by the United States Government or any agency thereof. The views and opinions of authors expressed herein do not necessarily state or reflect those of the United States Government or any agency thereof. 
TABIE I

Macropore Structural Properties of Illinois \#6 Chars Produced at Various Heating Rates

\begin{tabular}{|c|c|c|c|c|c|}
\hline $\begin{array}{l}\text { Heating } \\
\text { Rate }\end{array}$ & Porosity & $\begin{array}{c}\text { Surface Area } \\
\text { Density } \mathrm{S}_{\mathrm{v}} \\
\left(\mathrm{cm}^{2} / \mathrm{cm}^{3} \text { particle }\right)\end{array}$ & $\begin{array}{c}\text { Specific Surface } \\
\text { Area } \mathrm{S}_{\mathrm{g}} \\
\left(\mathrm{cm}^{2} / \mathrm{cm}^{3} \text { solid }\right)\end{array}$ & $\begin{array}{c}\text { Surface Area } \\
\text { Density } \mathrm{s}_{\mathrm{s}} \\
\left(\mathrm{cm}^{2} / \mathrm{cm}^{3} \text { particle }\right)\end{array}$ & $\begin{array}{l}\text { Maximum } \\
\text { Radius } \\
\quad(\mu \mathrm{m})\end{array}$ \\
\hline $\begin{array}{c}0.1 \\
1 . \\
10 . \\
100 . \\
1000 .\end{array}$ & $\begin{array}{l}0.356 \\
0.526 \\
0.709 \\
0.795 \\
0.873\end{array}$ & $\begin{array}{l}527 \\
759 \\
908 \\
700 \\
695\end{array}$ & $\begin{array}{r}822 \\
1,599 \\
3,116 \\
3,409 \\
5,470\end{array}$ & $\begin{array}{l}334 \\
521 \\
601 \\
396 \\
346\end{array}$ & $\begin{array}{l}135 \\
173 \\
153 \\
194 \\
224\end{array}$ \\
\hline
\end{tabular}

TABLE II

Macropore Structural Properties of Iignite Chars Produced at Various Heating Rates

\begin{tabular}{|c|c|c|c|c|c|}
\hline $\begin{array}{l}\text { Heating } \\
\text { Rate }\end{array}$ & Porosity & $\begin{array}{c}\text { Surface Area } \\
\text { Density } S_{v} \\
\left(\mathrm{~cm}^{2} / \mathrm{cm}^{3} \text { particle }\right)\end{array}$ & $\begin{array}{l}\text { Specific Surface } \\
\text { Area } \mathrm{S}_{\mathrm{g}} \\
\left(\mathrm{cm}^{2} / \mathrm{cm}^{3} \text { solid) }\right.\end{array}$ & $\begin{array}{c}\text { Surface Area } \\
\text { Density } \mathrm{S}_{\mathrm{s}} \\
\left(\mathrm{cm}^{2} / \mathrm{cm}^{3} \text { particle }\right)\end{array}$ & $\begin{array}{l}\text { Maximum } \\
\text { Radius } \\
\quad(\mu \mathrm{m})\end{array}$ \\
\hline $\begin{array}{c}0.1 \\
10 \\
1000\end{array}$ & $\begin{array}{l}0.140 \\
0.153 \\
0.195\end{array}$ & $\begin{array}{l}1,011 \\
1,107 \\
1,369\end{array}$ & $\begin{array}{l}1,176 \\
1,307 \\
1,700\end{array}$ & $\begin{array}{l}550 \\
598 \\
709\end{array}$ & $\begin{array}{l}31.0 \\
25.5 \\
25.6\end{array}$ \\
\hline
\end{tabular}

\section{Effects of Coal Particle Size}

Heat transfer in pyrolyzing coal particles can be significantly affected by the particle size. If external heat transfer controls the pyrolysis process, particle temperature will remain constant during heat-up and the heating rate will decrease with increasing particle size. On the other hand, if the rate of external heat transfer is high enough, high heating rates and large particle sizes can lead to significant temperature gradients within the particle. Under such conditions, the pyrolysis reaction rates will vary significantly inside the particles.

In order to quantify the effects of particle size on the macropore structure of chars produced from the Illinois $\$ 6$ coal, two additional size fractions of coal particles were pyrolyzed at $10^{\circ} \mathrm{C} / \mathrm{s}: 25-28 \mathrm{mesh}$ (589-710 $\mathrm{mm}$ particle diameter) and 100-120 mesh (125-149 $\mathrm{\mu m}$ particle diameter). Thus, the mass of individual particles varied by about two orders of magnitude for the pyrolysis runs at 10 ${ }^{\circ} \mathrm{C} / \mathrm{s}$. This heating rate was selected in order to facilitate the detection of differences in the pore structure possibly caused by changes in the internal heating rate of the particles.

Fig. 3 presents representative cross-sections of char particles produced from the additional runs at $10^{\circ} \mathrm{C} / \mathrm{s}$. A comparison of the cross-sections shown in Fig. 3 and Fig. $1 \mathrm{C}$ reveals very different pore structures for the three chars. For the smallest size fraction (Fig. 3A), we observe fewer pores per particle 
and the pore shape is rather rounded. The largest size fraction, on the other hand, exhibits numerous nacropores per particle. The boundaries of the pore profiles are very tortuous and we see again the characteristic cellular pore structure with small pores embedded in the walls separating the larger cavities.

Table III summarizes the measurements for the macropore properties. The interesting result here is that the macroporosity of the particles was not affected by their size. This indicates that particle size did not affect the internal heating rate, pointing out that external heat transfe: is not limiting for our pyrolysis reactor. The maximum pore radius observed fell from 284 um for the 25-28 mesh sample to $51 \mu \mathrm{m}$ for the 100-120 mesh sample. This decrease in macropore size was accompanied by an increase in the specific surface area of macropores per unit volume of char particle.

TABIE III

Effects of Coal Particle Size on the Macropore Structural Properties of Illinois \#6 Chars

\begin{tabular}{|c|c|c|c|c|c|}
\hline $\begin{array}{l}\text { Particle } \\
\text { Size } \\
\text { (mesh) }\end{array}$ & Porosity & $\begin{array}{c}\text { Surface Area } \\
\text { Density } \mathrm{S}_{\mathrm{y}} \\
\left(\mathrm{cm}^{2} / \mathrm{cm}^{3} \text { particle }\right)\end{array}$ & $\begin{array}{c}\text { Specific Surface } \\
\text { Area } \mathrm{S}_{\mathrm{g}} \\
\left(\mathrm{cm}^{2} / \mathrm{cm}^{3} \text { solid) }\right.\end{array}$ & $\begin{array}{c}\text { Surface Area } \\
\text { Density } S_{s} \\
\left(\mathrm{~cm}^{2} / \mathrm{cm}^{3} \text { particle }\right)\end{array}$ & $\begin{array}{l}\text { Maximum } \\
\text { Radius } \\
\quad(\mu \mathrm{m})\end{array}$ \\
\hline $\begin{array}{r}100-120 \\
50-60 \\
25-28\end{array}$ & $\begin{array}{l}0.689 \\
0.708 \\
0.688\end{array}$ & $\begin{array}{r}1,898 \\
908 \\
729\end{array}$ & $\begin{array}{l}6,106 \\
3,116 \\
2,339\end{array}$ & $\begin{array}{r}1,326 \\
601 \\
496\end{array}$ & $\begin{array}{l}50.5 \\
153 \\
351\end{array}$ \\
\hline
\end{tabular}

It must be noted here that maceral segregation may complicate the determination of particle size effects on the macropore structure of chars produced from plastic coals. Due to differences in the mechanical properties of the various coal macerals, grinding and sifting procedures may lead to enrichment of certain macerals in certain size fractions (i.e. small size fractions may contain more exinite). Thus, the well-known differences in the plastic behavior and volatile content of coal macerals can affect the macropore structure of different size fractions.

\section{TASK (B): GASIFICATION UNDER STRONG INTRAPARTICLE DIFEUSIONAI IIMITATIONS}

A thermogravimetric reactor was purchased and installed in our laboratory. Work has already started on the design and construction of a new furnace and heating system for our thermogravimetric reactor that will allow us to achieve higher heating rates than those achieved with the manufacturer's furnace. A prototype for the new heater controller is complete and will soon undergo testing. The digital control algorithms developed for our previous thermogravimetric reactor will be adjusted and tuned for the new instrument.

\section{TASR (C) : MATHEMATICAC MODELING AND MODEL VALIDATION}

Discrete models were developed to treat the problem of char gasification at high temperatures. Lon utilization of the surface area associated with the micropores is expected under such conditions, and the accessibility and surface area of the macropores become the dominant factors in determining the temporal evolution of reaction rates. 
Our earlier discrete models (Sandmann and zygourakis, 1988) defined the pores of a solid reactant (char) by overlapping regular geometrical entities (circles, spheres or cylinders) of a given size distribution. For example, two-dimensional simulations modeled the pore cross-sections as an assemblage of overlapping circles, grew the pores by increasing the circle diameters by a fixed amount at each time step and then determined which cells had to be changed (from char to pore) to reflect the new pore dimension. As shown in Eigs. 1 through 5, however, highly irregular pore structures are observed when char particle cross-sections are viewed under the microscope.

The new discrete models are based on an exosion algorithm and they avoid the computational complexities introduced when pores of arbitrary geometry are approximated by overlapping regular geometric entities. These models again employ a computational grid to represent the reacting porous solid and the macropores. However, the initial computational grids are obtained directly from digitized images of actual particle cross-sections viewed under the microscope. These images are accurate discrete approximations of a slice of the actual reacting solid. The incorporation of sophisticated digital image processing techniques in the gasification models is perhaps the most attractive feature of the new approach. For the runs presented below, the following assumptions were made.

- Only the surface area directly accessible to reactants from the irregular particle exterior participates in the reaction. Macropores in the particle interior are not initially available for reaction. When the reaction front reaches these interior pores, however, their surface area becomes available for reaction.

- Diffusional limitations in the macropores that are open to the exterior are neglected. This assumption is not expected to lead to significant errors in model predictions for the Illinois \#6 chars given the large size of their internal cavities.

- Internal pores for any cross-section do not become available for reaction due to burn-through occurring at planes above or below the studied one.

The last two assumptions have been relaxed in more recent versions of the erosion algorithm. At each simulation step, the computational grid is scanned and the surface area arailable for reaction is identified. A statistical method is then used to erode away a single layer of pixels corresponding to the char matrix from the exterior of the char particle (and from the exterior of all particle fragments). A $3 \times 3$ neighborhood around each char pixel is examined to determine whether or not it is on an edge boundary and should be reacted. The number of pixels reacting at each step is counted and the solid reactant conversion is calculated. This process can be repeated until a specified conversion has been achieved. Particle fragmentation can also be investigated with this model by idertifying all the isolated char fragments.

Fig. 4 presents the temporal evolution of reaction rates for the four particle cross sections presented in Fig. 1A. The dimensionless rate $R_{e}$ and time $\theta$ are defined as

$$
R_{e}=\frac{1}{m_{0}} \frac{d m}{d t} \Delta \tau \quad \theta=\frac{t}{\Delta \tau}=\frac{t R_{s}(c, T)}{\Delta x \rho_{s}}
$$

where $m_{0}$ is the mass of unreacted char, (dm/dt) is the rate of change of the reacting char mass, $R_{s}(C, T)$ is the intrinsic reaction rate per unit of surface area, $p_{s}$ is the density of the solid; $\Delta x$ is the pixel size of the image and $\Delta \tau$ is the time required to react a layer of solid with uniform thickness equal to $1 \mu \mathrm{m}$. 
The erosion rate for the particle exhibiting the large cenosphere (ILL106 in Fig. 1A) decreases initially and then jumps to very high levels when the large internal cavity opens up for reaction. At this point, the cross-section fragments considerably and disappears soon thereafter. The ILL102 particle in Fig. $1 \mathrm{~A}$ has several large cavities with thin walls separating them from the particle exterior. Thus, the erosion rates calculated for this cross-section jump to very high values as these cavities open up at fairly low conversions (less than 208) The ILL105 cross-section of Fig. 1A, on the other hand, exhibits numerous smaller cavities that open up for reaction at different time levels giving rise to the characteristic jumps in the reaction rate observed in the experiments by sundback et. al. (1984). In this case the reaction rates remain at relatively high levels for a large time interval. Finally, the more "solid" cross-section of Fig. IA (ILLI01) exhibits a steady decrease in erosion rate for a long period of time until the single large cavity opens up. A large jump in the erosion rate is observed at this point and the rate decreases slowly after achieving its maximum value. Another interesting observation from Fig. 4 concerns the wide range of particle burnout times predicted by the discrete simulations. These variations are clearly attributed to the large internal cavities and the different macroporosities of the individual particles.

Simulation results from runs on all particle sections can provide an indication of the expected average gasification behavior for a char sample. Fj.g. 5 presents the average reaction rate vs. time patterns for the three Illinois \#6 chars produced by pyrolyzing coal particles of different sizes at $10^{\circ} \mathrm{C} / \mathrm{s}$. Due to its small particle size and large external surface area, the 100-120 mesh sample exhibits a high initial rate, a sharp rate maximum and very short reaction times. As the particle size is increased, the reaction rates decrease and their burnout times increase significantly.

\section{SUMMARY AND HIGHLIGHT ACCOMPIISHMENTS}

Particles from two parent coals (Illinois \#6 and lignite) were pyrolyzed in a nitrogen atmosphere using a captive sample microreactor capable of achieving heating rates as high as $1000^{\circ} \mathrm{C} / \mathrm{s}$. Direct measurements on digitized images of char particle cross-sections and a stereological model were used to characterize the macropore structure of chars. Macroporosities, pore size distributions and surface areas were accurately measured allowing us to quantify the effects of pyrolysis heating rates and coal particle size. We have paid particular attention to the development of image analysis software that has allowed us to analyze for the first time the shape or boundary tortuosity of the macropores. Tortuous pore boundaries result in higher values for the true macropore surface areas and should enhance the reactivity of the char samples. Another contribution of the current research program is the development of probabilistic gasification models that work on computational grids obtained from digitized images of actual cross-sections of char particles. These digital images are accurate discrete approximations of a slice of the actual reacting solid. The incorporation of sophisticated image processing techniques is perhaps the most attractive feature of the new simulation approach. Preliminary results indicate that the probabilistic models can accurately account for the opening of closed porosity and fragmentation phenomena occurring during gasification at high temperatures.

\section{PLANS EOR THE COMING YEAR}

The pyrolysis studies $w i l l$ be extended to include reactive $\mathrm{O}_{2} / \mathrm{N}_{2}$ atmospheres. Gasification experiments in the thermogravimetric and the microscope hot-stage reactor will be performed, and the image analysis software will be enhanced to allow quantitative measurements of dynamic reaction and fragmentation 
phenomena. The obtained experimental data will be compared to the theoretical predictions of our probabilistic models. These systematic studies will establish how the macropore structure affects the reactivity pattern and the size distribution of fragments obtained during gasification at high temperatures. Tile reactivity and fragmentation data will provide essential parameters for the optimal design of coal utilization processes.

\section{REEERENCES}

Gavalas, G.R. and Wilks, K.A., AIChE J., 26, 201 (1980).

Hamilton, L.H., Euel, 60, 955 (1981).

DeHoff, R.T., J. Microscopy, 131, 259 (1983).

Howard, J.B., "Fundamentals of Coal Pyrolysis and Hydropyrolysis", in Chemistry of Coal Utilization, p. 665, Elliott, M.A., Ed., John Wiley (1981).

Oh, M., Peters, W.A. and Howard, J.B., Procs. 1983 International Conference on Coal Science, F. 483, International Energy Agency (1983).

Sandmann, C.W. and Zygourakis, K., AIChE J., in press (1988).

Sundback, C.A., Beer, J.M. and Sarofim, A.F., Procs. 20th International Sympo-

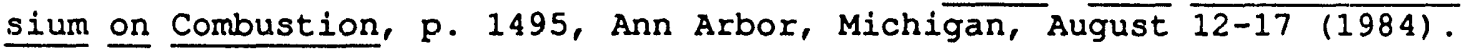

Taylor, C.C., J. Microscopy, 132, 57 (1983).

Weibel, E.R., "Stereological Methods", vol. 2, Academic Press (1980). 

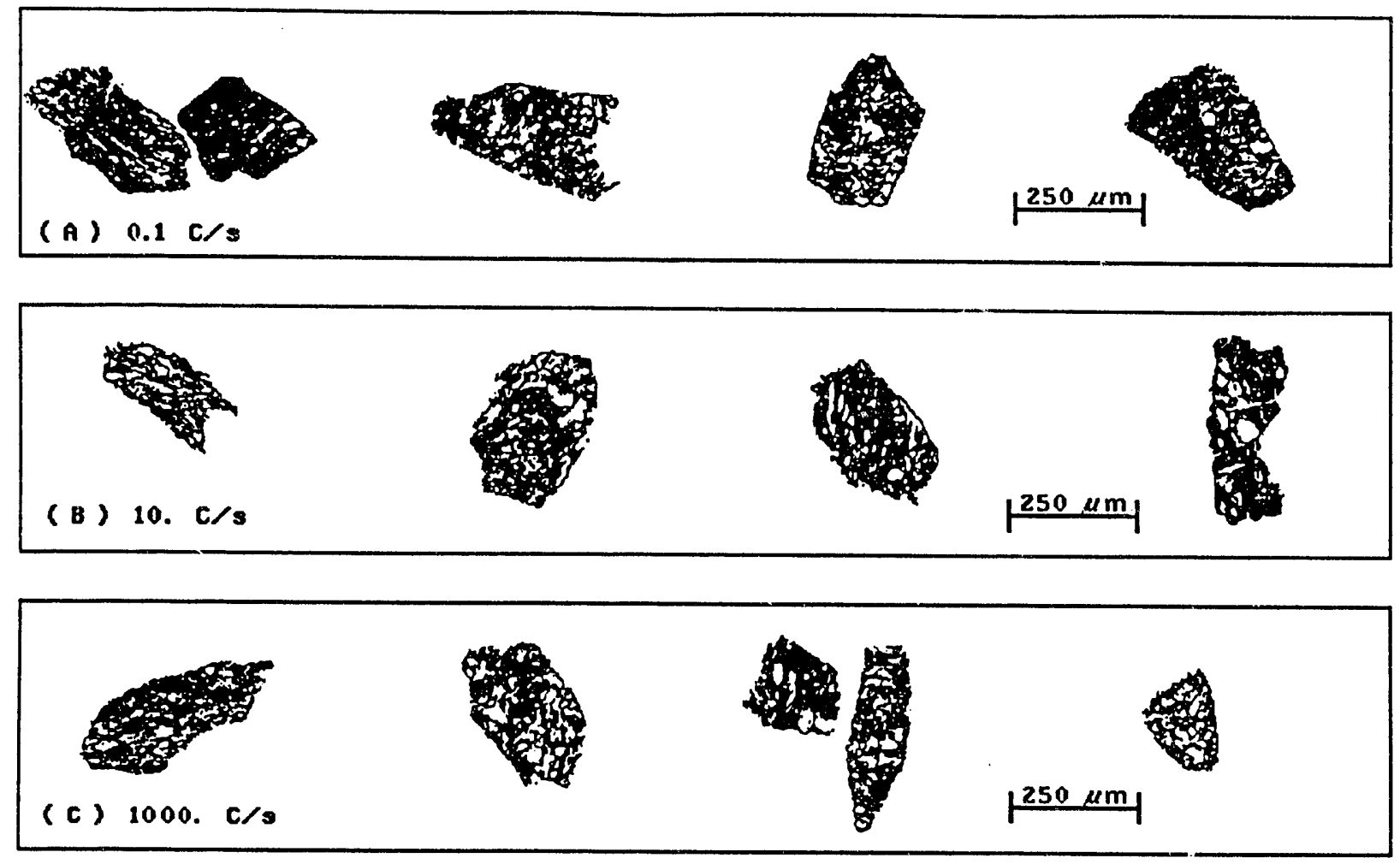

Figure 2: Binary images of particle cross-sections for lignite chars produced at various pyrolysis heating rates (Coal particle size: 50-60 mesh).

(A) PARTICLE SIZE: $100-120$ mesh

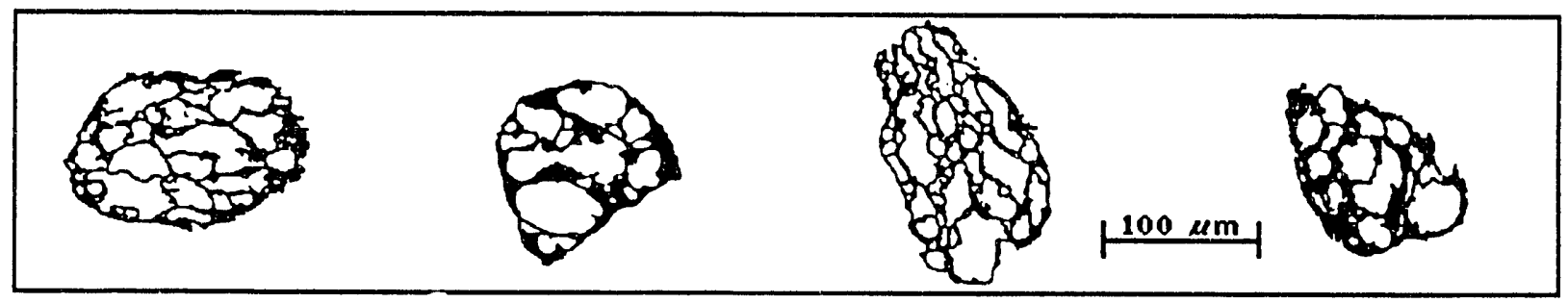

(B) PARTICLE SIZE: $25-28$ mesh

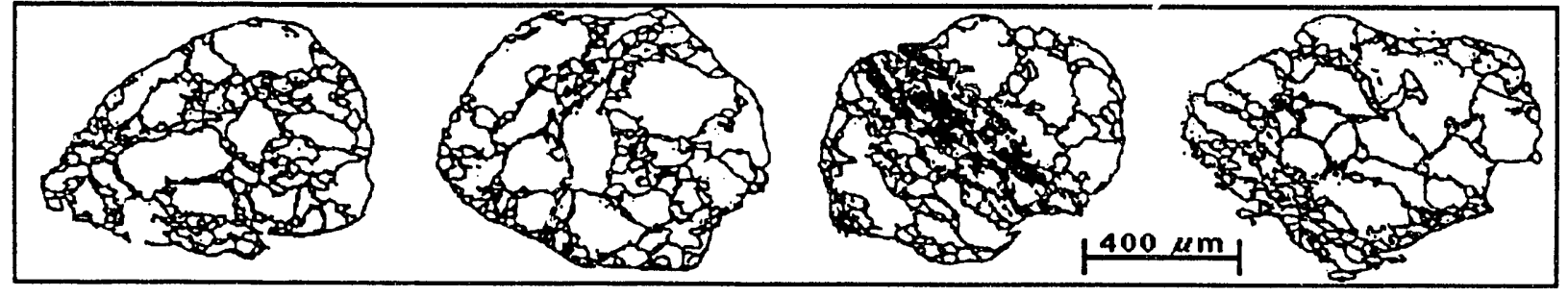

Figure 3: Binary images of particle cross-sections for Illinois \#6 chars produced f:om different sizes of coal particles (Heating Rate: $10^{\circ} \mathrm{C} / \mathrm{s}$ ). 


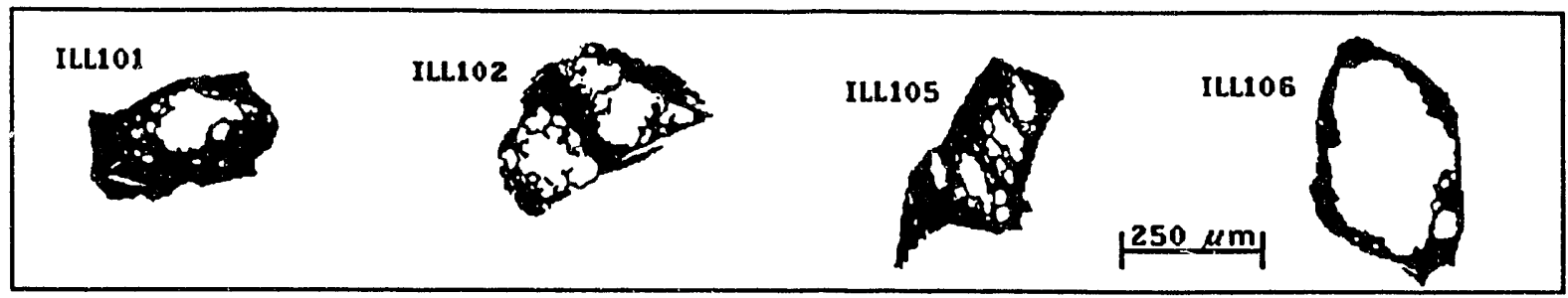

( ค ) $0.1 \mathrm{c} / \mathrm{s}$

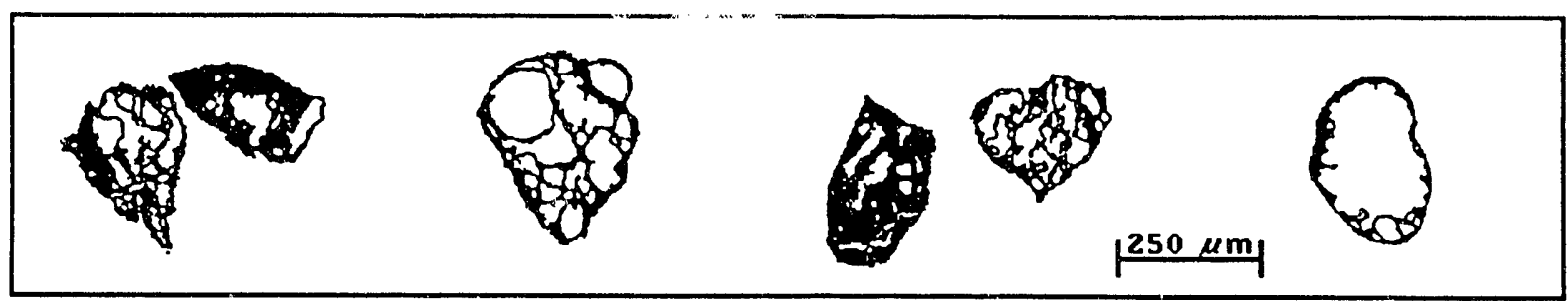

( В ) $1.0 \mathrm{c} / \mathrm{s}$

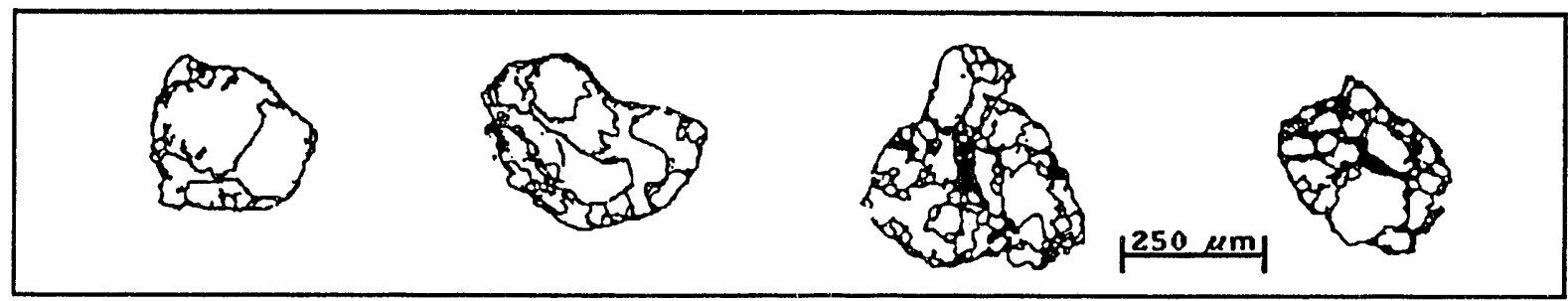

(C) $10 . \mathrm{c} / \mathrm{s}$

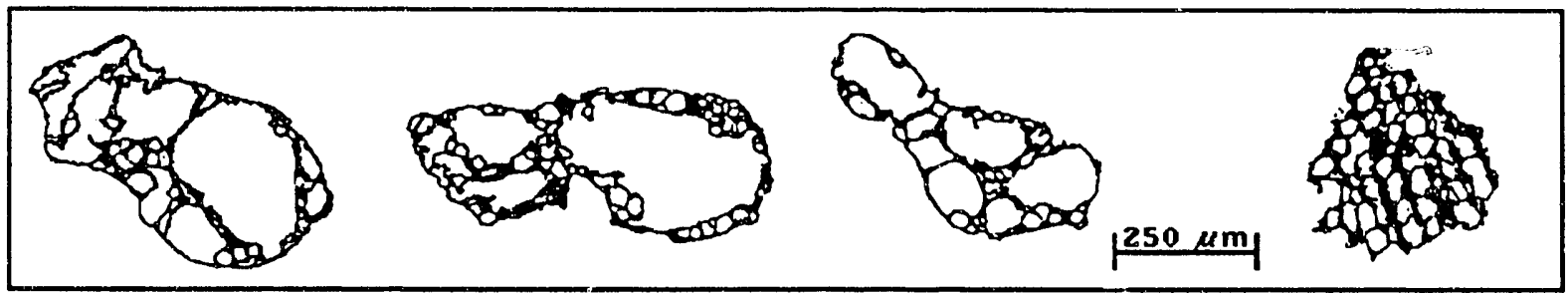

( D ) $100 . \mathrm{c} / \mathrm{s}$

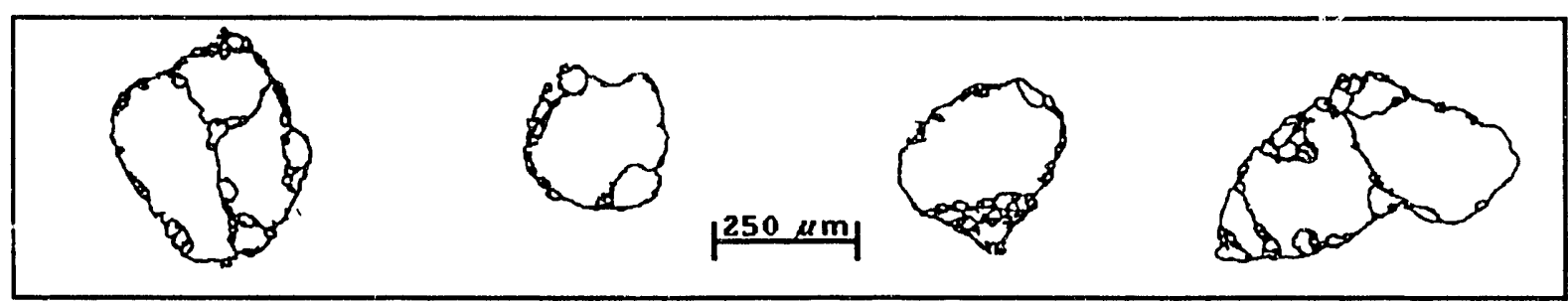

(E) $1000 . \mathrm{C} / \mathrm{s}$

Figure 1: Binary images of particle cross-sections for Illinois \#6 chars produced at various pyrolysis heating rates (Coal particle size: 50-60 mesh). 


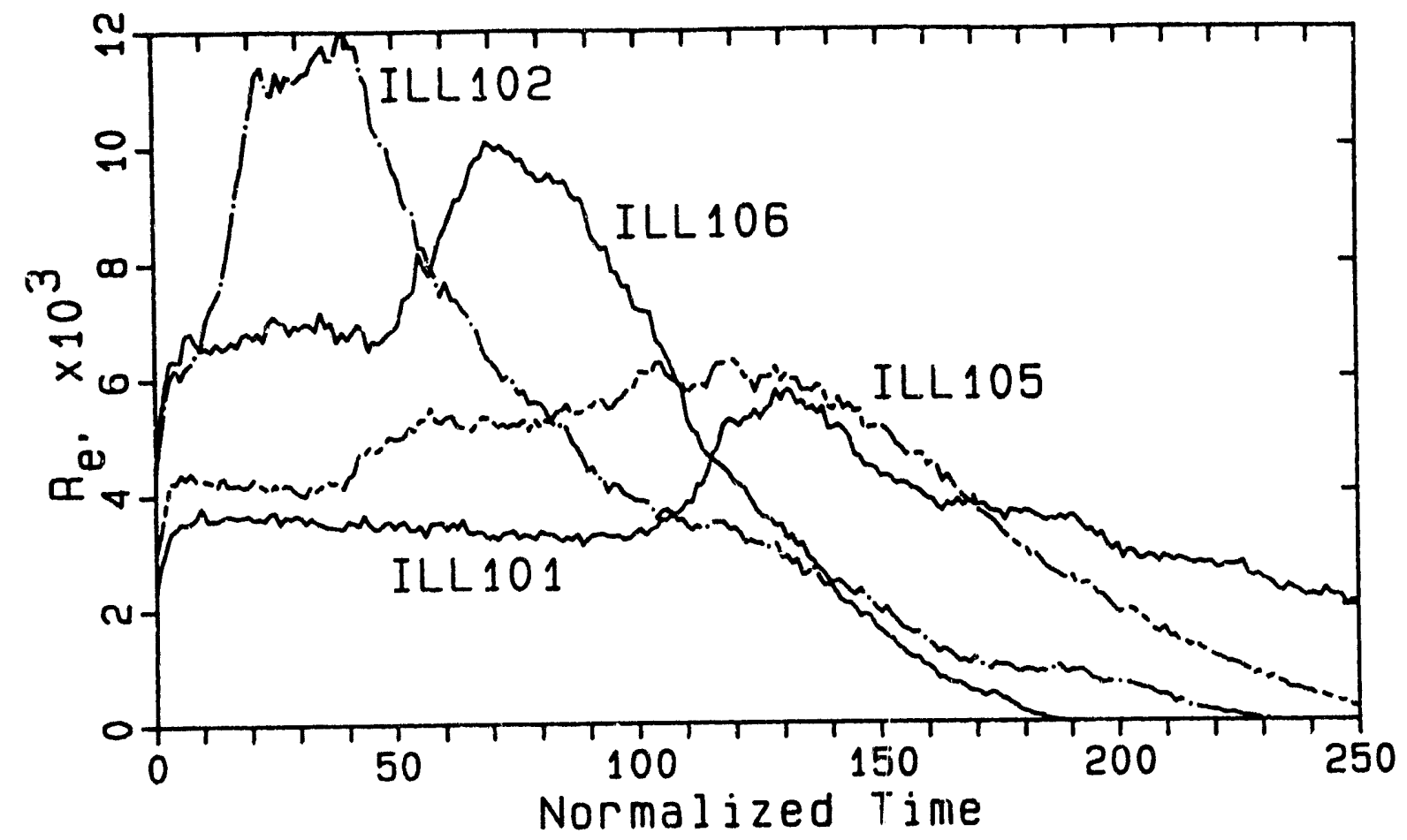

Figure 4: Temporal evolution of predicted reaction rates from four simulation runs with Illinois *6 char particles.

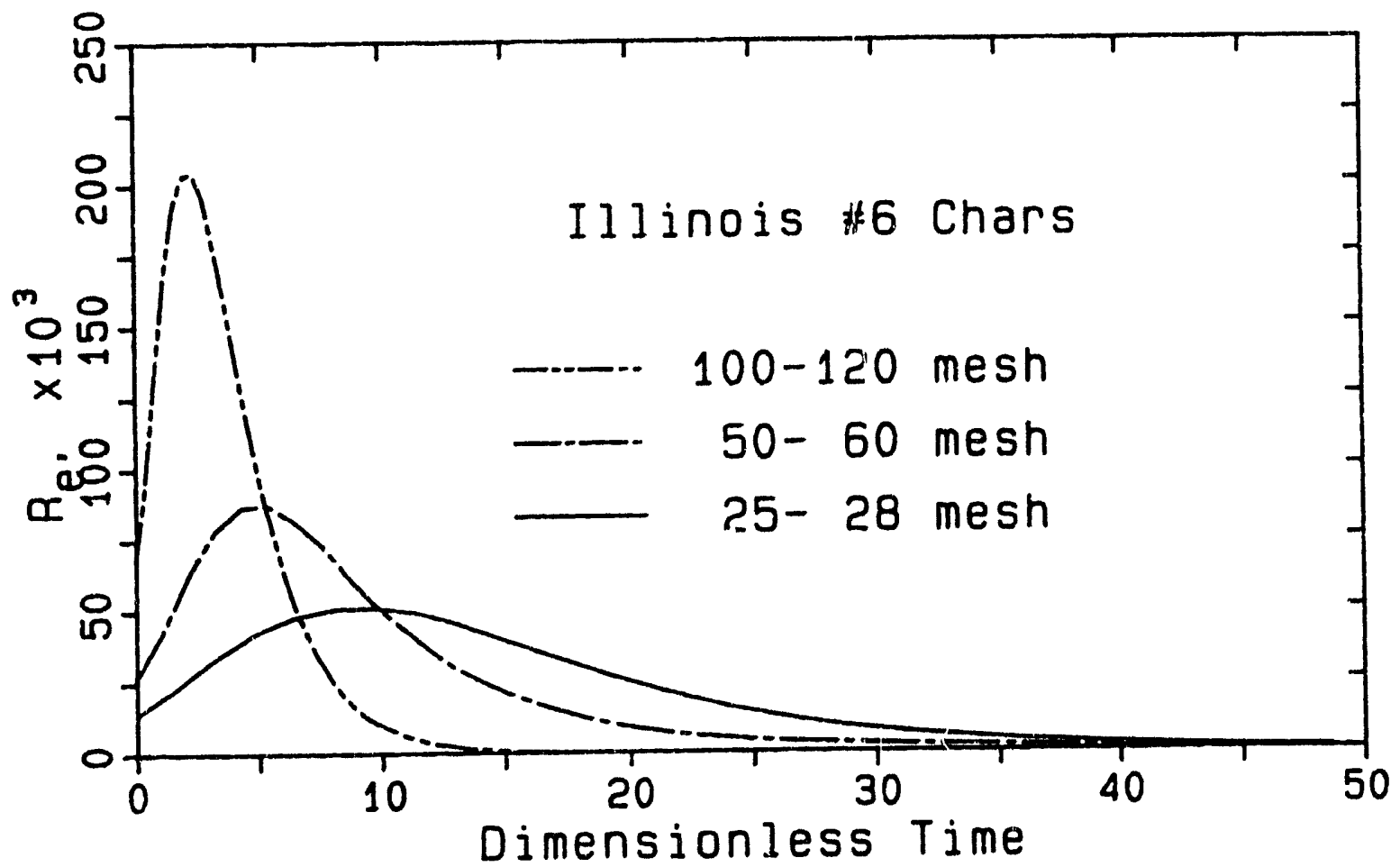

Figure 5: Effect of coal particle size on the reaction rates predicted for three Illinois 6 chars. Model predictions are averages for 48 particle cross-sections. 

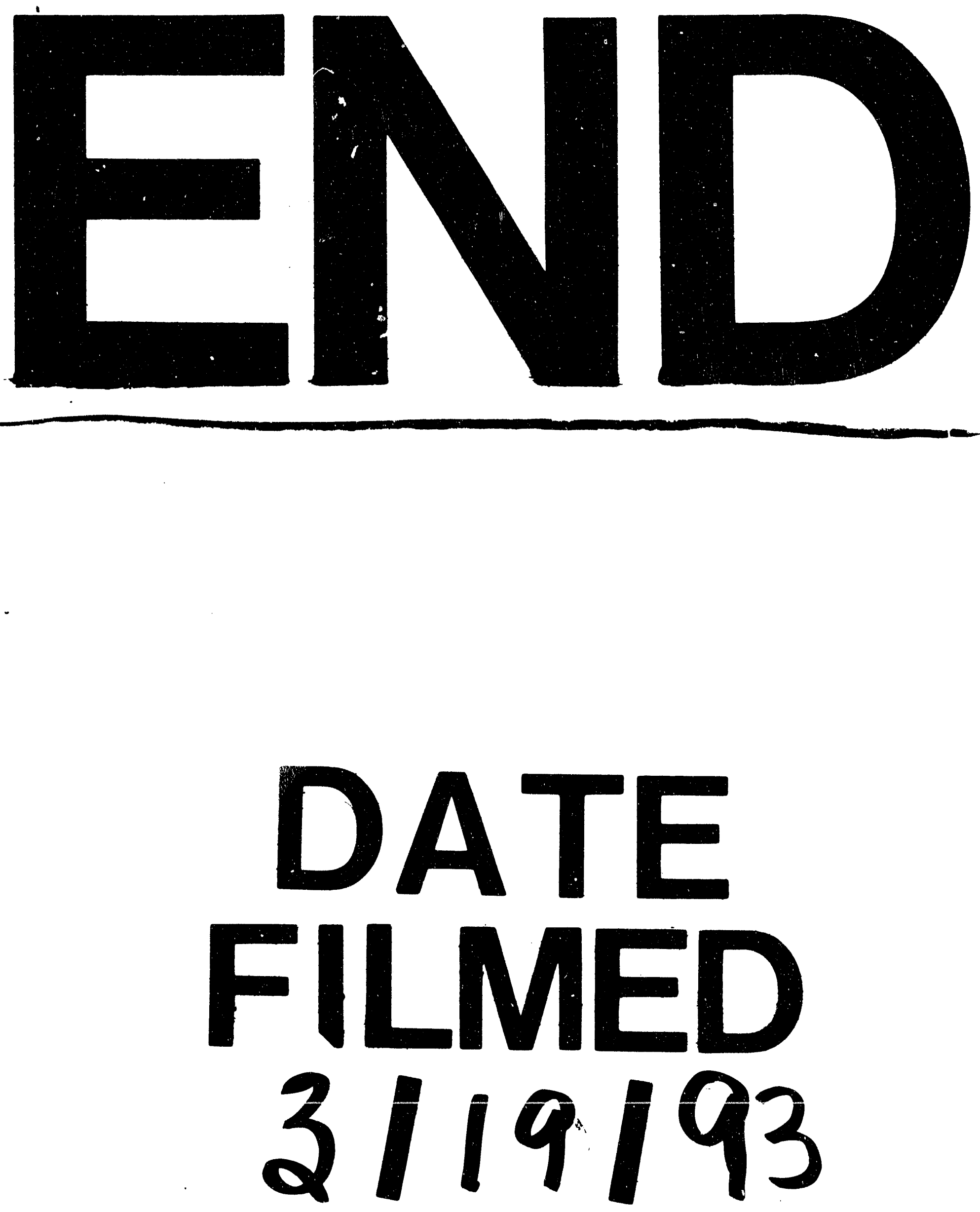


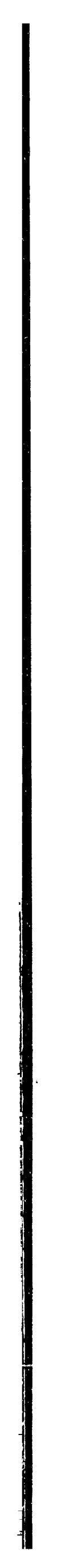

\begin{tabular}{|r|r}
$\mid$ & $\mid$ \\
$\mid$ & $\mid$
\end{tabular} 